\title{
Wire Fencing (Part 1): Determinants of Wire Quality
}

\author{
D. Pons ${ }^{*}$, G. Bayley, R. Laurenson, M. Hunt, C. Tyree, D. Aitchison
}

Department of Mechanical Engineering, University of Canterbury, New Zealand

\begin{abstract}
Knotted wire fences are fabricated on specialised machines. The input material is typically galvanised steel wire. However, the quality of the input wire used by the Fence Producer is beyond control of the Machine Manufacturer. The problem is that wire strand breakages have been reported during fabrication and subsequent field erection. This is an issue for the Fence Producer because of the lost productivity, and the potential for reputation (brand) damage for both the Manufacturer and Producer. While existing standards do exist for wire, even wire that meets these standards is known to fail during fence fabrication. Thus there is a need to better understand how the quality of wire affects the manufacturability of fences, and to identify, or if necessary create, a test for wire quality that is able to be conducted by Fence Producers. In this research, samples were obtained from known good and failed fences and wire coils, and subjected to a variety of physical and metallurgical tests. These were then statistically examined and compared to the known fate of the fence, to determine the sensitivity of the test. Four potential tests were evaluated: Tensile strength (UTS), ductility, 3-point bending, microstructural, impact energy, plus a fifth novel new test called linear torsional ductility (LTD). From these tests, it was evident that the linear torsional ductility test was the most sensitive and reliable indicator for wire quality. This paper is part of a collection, with companion papers examining material properties of wire, microstructure, impact energy for wire, knot performance, and the testing of whole fences.
\end{abstract}

Keywords: Wire, fence, material test.

\section{INTRODUCTION}

\subsection{Context}

Knotted wire fences are used throughout the world for retention of livestock. Other types of wire fencing include single strands, diamond (chain link), welded mesh and hexagonal mesh (chicken mesh). However the subject of the present paper is only rectangular knotted mesh, with a particular emphasis on the production thereof.

As an agricultural product, the primary body of knowledge on fencing has historically resided in national standards, e.g. $[1,2]$, with a particular focus on the geometric parameters of the fence and the coatings. The corrosion resistance of wire fences in exposed environments has been of interest for many years [3-9] and still continues to be an area of research as material science has made newer coatings available $[10,11]$.

\subsection{Production Machinery}

From the outset there has also been interest in the production process and the machinery required for fabricating the fences [12-14] but this area of research has historically been somewhat neglected. More recently the machines have increased in performance and functionality, see Fig. (1) for a typical modern machine. These now have a high degree of electrical-mechanical-electronic integration, so new issues

*Address correspondence to this author at the Department of Mechanical Engineering, University of Canterbury, Private Bag 4800, Christchurch 8020, New Zealand, Tel: +64 33642987 x 7214; Fax: +64 3364 2078; Email: dirk.pons@canterbury.ac.nz.

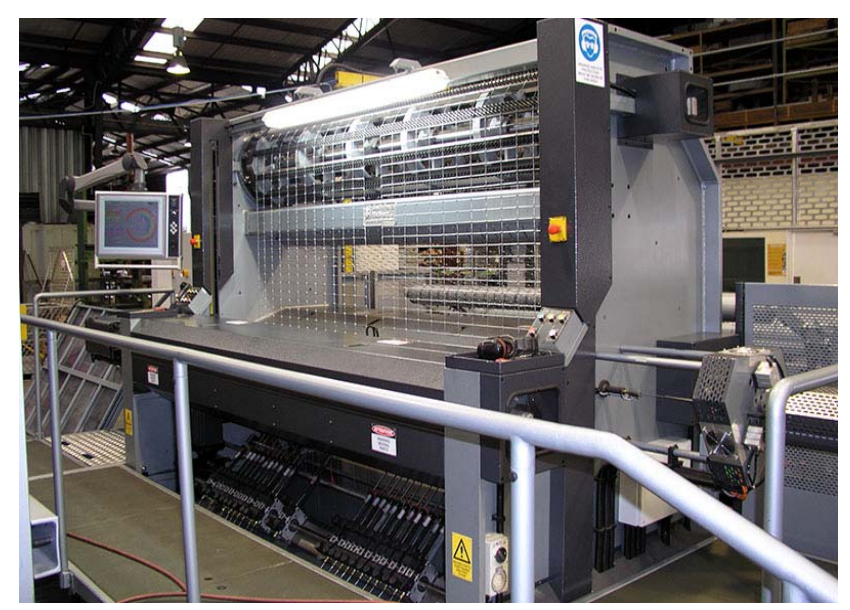

Fig. (1). Example of a specialised machine for knitting wire fences. Various knot types are available: this particular machine produces a fence with a 'stiff-stay' knot. The image hardly does justice to the size, complexity, and engineering precision of these specialised machines. This particular machine is designed and manufactured by South Fence Machinery (New Zealand). (Image used by permission of that firm).

arise [15]. There is also much proprietary commercial knowledge, but this is inaccessible to the industry as a whole.

The machines assemble several continuous longitudinal strands (line wires) and link them together, at set spacings, with vertical wires (stay wires) to create a characteristic rectangular mesh shape. Complexity arises in the way the knots are formed. Various types of knot may be used, with different effects on the overall fence properties. Examples of Knot type options include: Fixed Knot, Stiff Stay, Hinge Joint, see 

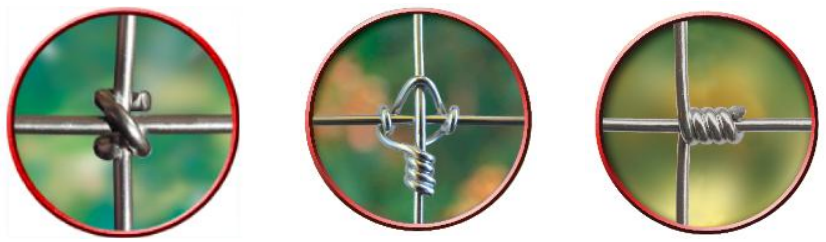

Fig. (2). Selection of knots used in the fabrication of rectangular netted wire fencing. From left: stiff-stay, fixed, and hinge-joint knot. Each knot has its own unique characteristics which see them used for different applications. These knots require dedicated tooling and hence consideration at the early stages of the design of the machine. (Image courtesy South Fence Machinery (New Zealand))

Fig. (2). The machines are dynamically configurable for different mesh sizes and to accommodate various wire diameters, however the knot-type is determined at design-time and fixed in the press-tool.

The input material for knotted fences is typically galvanized steel wire, often of high tensile strength, and provided in coil form. The focus of this paper is on manufacturing of this fence product, and particularly the quality requirements for the input material.

\subsection{Definition of the Problem}

The nature of the wire-fencing industry is that different parties factors are typically responsible for the various stages of getting the product into use: Machine Manufacturer (design \& build of the specialised knitting machines), Wire Producer (supplies coils of raw wire), Fence Producer (operation of machines to produce rolls of fencing), Distributor (distribution and sales of fencing through a rural network), Fencing Contractor (erection of fencing), the Farmer using the product, and finally the type of Livestock being contained.

The degree of specialization is therefore high: each producer is only doing their part of a large value-added chain. This has consequences from the perspective of the Machine Manufacturer. Specifically, the quality of the input wire used by the Fence Producer is beyond control, as is the treatment of the fence during distribution and erection. The problem is that wire strand breakages occur during fabrication and in end-use applications. This is an issue for the Fence Producer because of the lost productivity during fabrication and the potential for reputation (brand) damage for both the Manufacturer and Producer if there are field failures. It is often difficult to identify the cause of breakage in a specific case. For breakages during production it can be the quality of the input wire, the treatment it receives from the machine (crimp, knot, and cut), or production settings (machine speed, operator settings). For field failures it can be the handling of the product during distribution, the fence-erection, or the service forces. Therefore the quality of the input raw wire is important.

\subsection{Existing Approaches to Wire Quality}

Fencing wire has existed for a long time. However there is no active research literature. The only body of knowledge is that contained within the standards and proprietary commercial experience, the latter being inaccessible to the industry as a whole.
Wire quality is currently only controlled by tensile strength and coating properties in standards. For the New Zealand jurisdiction under investigation the relevant standards are AS 1650 [16] and NZS 3471 [17]. Other comparable standards exist in other countries.

The problem is that even wire that meets these standards is known to occasionally fail during production. So evidently there are more determinants of wire quality than simply tensile strength and coating properties. That may be relatively obvious in hindsight, but the difficulty for the various stakeholders is in objectively determining those factors, and in finding the wire property that is a sensitive and reliable indicator of whether or not wire will fail during production and in subsequent field applications.

\subsection{Purpose: Need for Better Operation Tests for Wire Quality}

Thus there is a need to better understand how the quality of wire affects the manufacturability and in-field durability of fabricated fences. The first purpose of this research was therefore to determine which wire properties most influence fence manufacturability. (A companion paper addresses infield forces due to erection and livestock retention.)

The second purpose was to identify, or if necessary create, a test for wire quality that is able to be operated by Fence Producers. Quality tests that are too difficult to execute tend to performed infrequently or not at all. In this production environment a simple quick test that can be performed on every batch of wire, without large capital investment, is highly desirable. Technologies like electron microscopy do not meet this criterion, although otherwise useful for specialised investigations.

\section{METHOD}

The approach taken was first to obtain samples of known good and failed fences. Samples were of complete fence panels and wire coils, and covered a variety of input wire batches and brands. To reduce external variability, all fence panels had been produced by the same Producer on machines from one Manufacturer, the latter being South Fence Machinery Ltd (New Zealand).

Specimens were cut from these fences or coils, and subject to a variety of physical and metallurgical tests. These were then statistically examined and compared to the known fate of the fence, to determine the sensitivity of the test.

Wire properties were evaluated using the following tests:

○ Tensile Tests (UTS, Percent Elongation (Ductility), Young's Modulus)

○ Three-point Bending Tests (Flexural Modulus)

- Microstructural Analysis (hardness, microstructure irregularities)

- Impact Energy Tests

The present paper provides an overview of the tests performed, and proposes a novel alternative test, the Linear Torsional Ductility Test (LTD). Companion papers describe the materials testing results in more detail, as well as the testing of service forces in whole fences. 


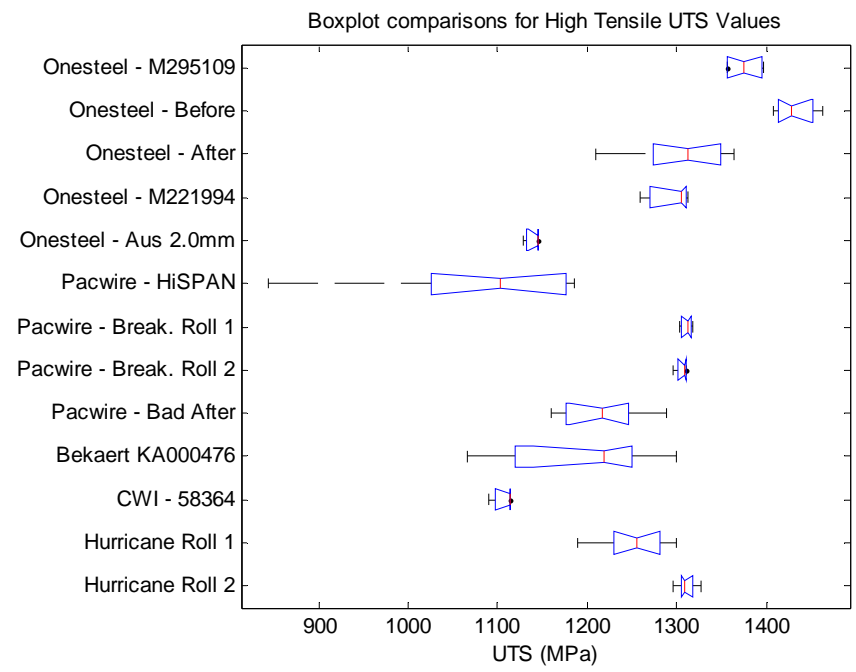

Fig. (3). Boxplot depicting UTS results from tensile tests.

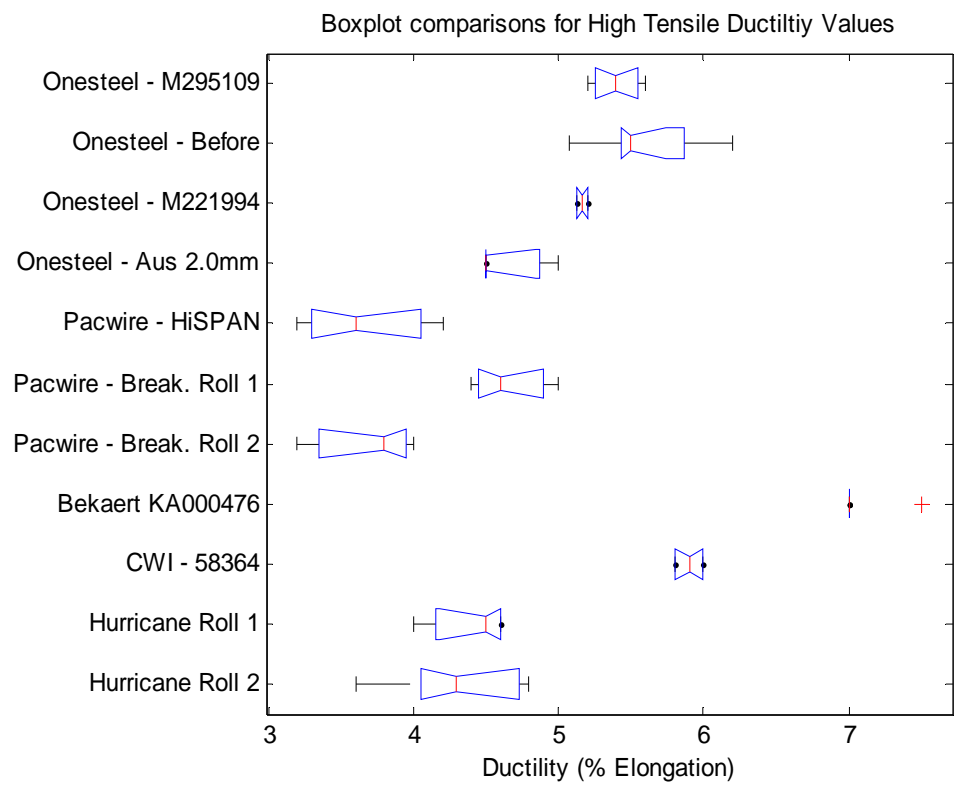

Fig. (4). Boxplot depicting percent elongation results from tensile tests

\section{RESULTS}

All tests have been carried out using their own individual procedures. For more details see companion papers. The results and findings for each respective materials test are discussed below.

\subsection{Tensile Testing}

In terms of implementation, the tensile test procedure is relatively straightforward. Any conventional tensile testing setup can be implemented to attain repeatable results. The only difficulty encountered was that specialty wire clamps were required to obtain accurate UTS values. Standard specimen grips are too harsh on wire, introducing stress concentrations that lead to premature failure.

British Wire Standard EN 10223-5 [18] stipulates that $2.5 \mathrm{~mm}$ High Tensile wire must have a minimum UTS of $1050 \mathrm{MPa}$ [18]. Fig. (3) shows that most wire batches exceed this performance criterion (there were exceptions).
In terms of the tests power, there was observed to be a $25 \%$ difference in UTS between the highest performing Onesteel-Before wire batch and the worst performing Pacwire HiSPAN wire batch. The variance in this difference in means was found to be $7.7 \%$. Despite this obvious difference, it must also be noted that another 'common' wire batch, Pacwire Breaking Roll 2, has a UTS similar to known 'good' Onesteel batches.

However on statistical grounds, it is concluded that Tensile UTS is not a sensitive and reliable measure of wire quality.

\subsection{Ductility}

Fig. (4) shows the percentage elongation (ductility) results as part of the tensile tests, taken from a $250 \mathrm{~mm}$ gauge length.

NZS 3471:1994 stipulates that the ductility (over a $250 \mathrm{~mm}$ gauge) should not fall below $4 \%$ [19]. A minimum amount of ductility is required to prevent brittle failures. Too 


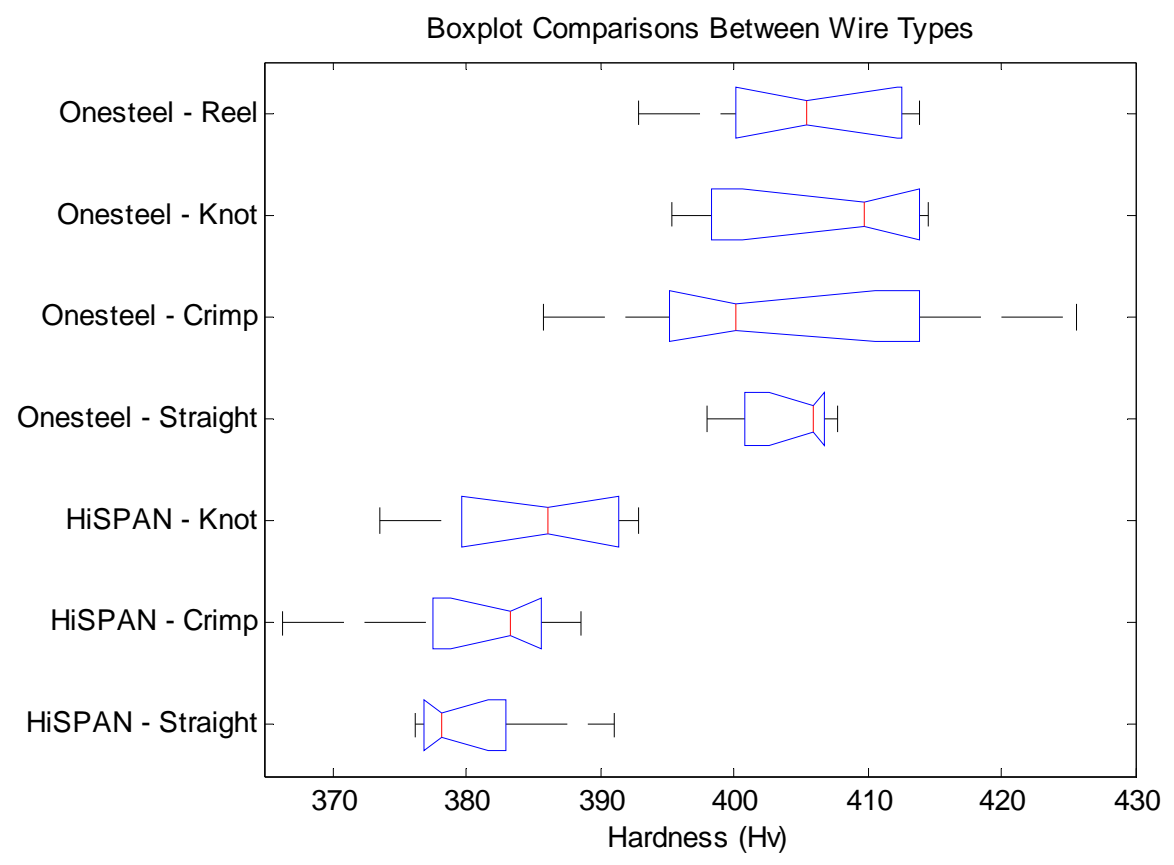

Fig. (5). Contains the flexural moduli results from the three-point bending investigation.

much ductility and the wire is prone to stretching, resulting in 'baggy fences' in the field. The figure shows that the $\mathrm{Pa}-$ cific Steel batches feature the lowest ductility. Indeed, both the HiSPAN and Breaking Roll 2 batches fail to meet the 4\% minimum ductility threshold. As expected, the 'good' Onesteel batches both have superior ductility, at approximately $5.5 \%$. Indeed, the difference between Onesteel - Before and Pacwire HiSPAN means was found to be $35 \%$. Bekaert and CWI which had both performed averagely in the UTS test showed significant amounts of elongation with $7 \%$ and $5.9 \%$ respectively. The results for Hurricane wire batches show that despite the claimed 'brittleness', both have a ductility of $4.35 \%$ which is above the standard.

Although these results support the case for ductility being a sensitive measure of wire quality, ductility is not the single most important factor in wire quality. For this reason, ductility needs to be specified in conjunction with other wire parameters, otherwise it could be spuriously interpreted that soft wires are always better than any High Tensile wire.

\subsection{Flexural Modulus}

The three-point bend test was used to determine the flexural modulus, $\mathrm{E}_{\mathrm{f}}$ of a wire sample in bending. This somewhat replicates the process whereby the line wire is bent around the vertical stay wires in an extreme loading situation.

Fig. (5) Boxplot depicting flexural modulus results from 3 -point bending tests, using a bending span of $25 \mathrm{~mm}$.

The three-point bending test results show that no real trends exist between the different wire brands/batches, as there is a high degree of variability. The boxplot also highlights the variability that was observed during the testing phase. The source of this variability is unknown, since all known variables were maintained constant (such as span, cross-head displacement etc.). One possible reason is that the apparatus used (MTS 810 Material Testing System) was not sensitive enough for the testing of these small cross-section wire samples in bending. The resulting load-deflection graphs did contain some load fluctuation, which made curve fitting to the linear section of the graph less accurate. Since the flexural modulus is highly sensitive to variations in the initial slope, it is possible that the fluctuations are the source of the observed variability. The only way to test this would be to replicate the tests on a smaller, more sensitive compression testing setup.

Due to the observed variability and lack of statistically significant outcomes between known 'good' and 'common' batches, the flexural modulus test in its current form is not an accurate and reliable indicator of predicting the performance of wire. It also infers that bending alone is not the cause of failures during manufacture or in service.

\subsection{Micro-Hardness}

Fig. (6) depicts the average results from the microhardness tests. This figure shows 'common' Pacific Steel wire to be consistently softer than 'good' Onesteel for the same locations. It also shows that the Pacific Steel wire is highly variable.

One further point to note is the correlation between UTS and Hardness. Generally, the UTS of ferritic steels can be inferred from hardness readings through the use of conversion charts. British Standard EN10218-1: 1994 states that for wire diameters below $4.0 \mathrm{~mm}$, no meaningful relationship exists between hardness and UTS [20].

In terms of test power, micro-hardness performs poorly (see Discussion). This finding is not much of a disappointment when implementation is considered, since microhardness testing is a labour intensive process. Samples have to be mounted into a plastic mould, ground, polished and then micro-hardness tested. Each step requires the use of special equipment, which is not readily available, and the process is time consuming. It unsuitable as a routine quality control measure. 


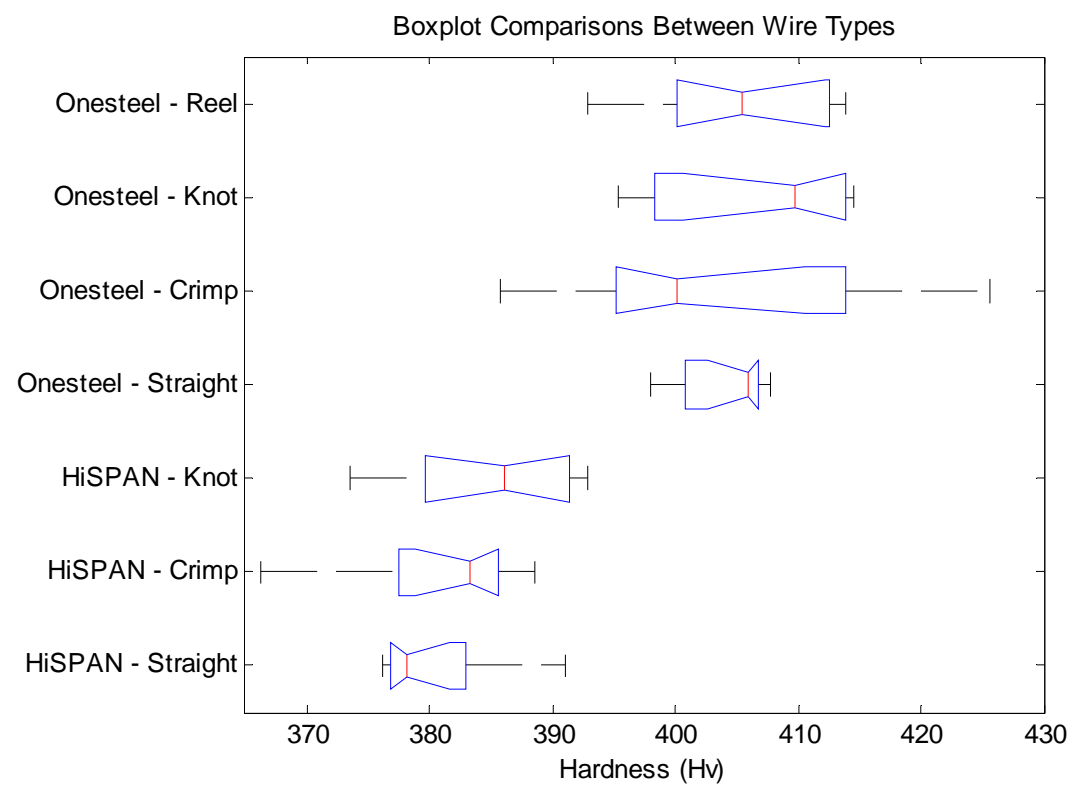

Fig. (6). Boxplot depicting microhardness values for 'good' Onesteel and 'common' Pacific Steel wire batches.

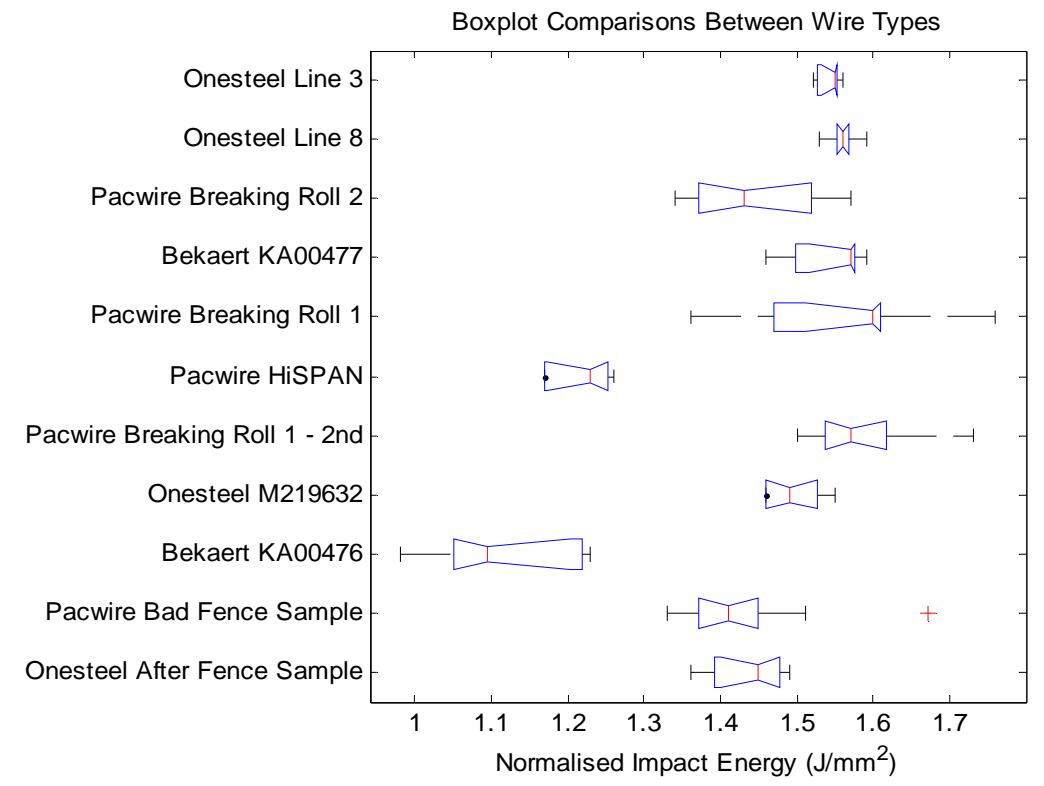

Fig. (7). Boxplot depicting normalised impact energies for a range of wire batches.

\subsection{Impact Energy}

Unfortunately, the standardised Charpy Impact Test is not directly applicable to wire products. The minimum specimen size is an $8 \mathrm{~mm}$ diameter rod, still significantly larger than any fencing wire sample. To overcome this issue, a custom rig was designed and tested specifically for testing fencing wire products. However, the issue of repeatedly notching wire samples was not overcome.

Fig. (7) depicts the results from the impact energy investigation. The results show that in general, the 'good' Onesteel wire batches absorb more energy during fracture (i.e. are tougher) than the 'common' Pacwire batches.

However, from a statistical perspective, the observed differences are not all statistically significant. The normalised impact energy of Onesteel Line 8 is found to be $21.8 \%$ higher than for Pacwire HiSPAN. The variation in this difference is only $11 \%$, which is comparable with that of the UTS and ductility tests.

Unexpectedly, the known 'common' Pacwire Breaking Roll 2 was not found to be significantly different from the known 'good' wire batches. The reason for this is because both Breaking Rolls were observed to be highly variable between tests.

In terms of test implementation, impact energy is a simple, elegant and quick test that requires little operator skill, and the equipment requirements are not onerous. Wire specimens are also small, which means that large sample sizes can be tested, a requirement for statistical methods. However it is not a particularly powerful discriminator from a statistical perspective. 
4. LINEAR TORSIONAL DUCTILITY (LTD): A NEW TEST

\subsection{Background}

None of the above tests have the dual attributes needed: sufficient statistical power to discriminate between good and poor wire, and ease of use in a production environment.

Therefore it was necessary to consider whether better tests could be devised. Somewhat serendipitously such a test was indeed discovered while devising novel torsion tests and we call this the Linear Torsional Ductility (LTD) test. The wire industry already has a standard wire wrap test, which involves tightly wrapping a wire specimen around a specified diameter mandrel (often the wire itself) for a specified number of turns [21]. The question we asked was: "since torsional stresses are induced in springs, why not create a test which builds on the industry wrap test, by pulling on the resultant close-bound spring?"

The existing wire wrap test simply involves wrapping the wire into a coil, and the LTD builds on this foundation. The innovative component of the LTD test is that the resulting wrap specimen is subsequently elongated in spring tension, e.g. in a tensile testing machine. Whereas the plain wrap-test is single-direction application of plastic-ductility, the LTD test applies an additional torsion stress after the workhardening episode. Once a spring is formed, the test is easily conducted in any tensile testing system, or indeed in any system (e.g. hydraulic puller) that can stretch the coil. It is important to note that the test only measures the length of the specimen: the actual force is not required. So a laboratory tensile testing machine is unnecessary.

The results of a LTD test are measured by a G Factor metric: the ratio of before and after helix pitch:

G Factor $=\frac{\text { Final Helix Pitch }}{\text { Initial Helix Pitch }}$
The LTD test apparatus is simple, and drawings of the prototype are given in a companion paper. The apparatus as presented here is manually operated, and tests, not shown here, confirm that results are not statistically sensitive to operator style and wrapping rate within reasonable operation. A standardised operating procedure was developed.

\subsection{Results}

The results from the LTD test are presented in Fig. (8) below.

Known 'good' Onesteel wire batches consistently outperform all of the other batches, always scoring a G Factor above 6. On the other hand, the 'common' Lumpy Pacwire, HiSPAN and Hurricane wire batches are observed to have greater test variability. Despite this, the tests still consistently score below $\mathrm{G}=5$. Once again, the Pacwire Breaking Roll 1 batch proves that it is of reputable quality, scoring above 6 . Interestingly, the Pacwire Breaking Roll 2 wire batch appears to perform slightly better than in other material tests.

The 'Lumpy Pacwire' batch deserves to be mentioned specially. A sample of this batch was obtained after it was rejected for having large galvanising defects on its surface, which prevented it from passing through the fence-knotting machines. Performing LTD tests on wire from this batch was interesting for a number of reasons. Not explicitly obvious in the above figure is the fact that this batch was the only one to encounter wire specimens prematurely breaking during wrapping onto the mandrel. Samples from this batch that did manage to wrap were however, observed to have a flaking galvanising coating. Under the ISO 7802 standard, this also constitutes a failed wrap test result.

After statistical analysis of all test outcomes, it was found that the results suggest that a G Factor of 5.0 marks the boundary between known good and poor quality wire. This threshold was found to minimise the possibility of obtaining type I (false positive) and type II (false negative) errors.

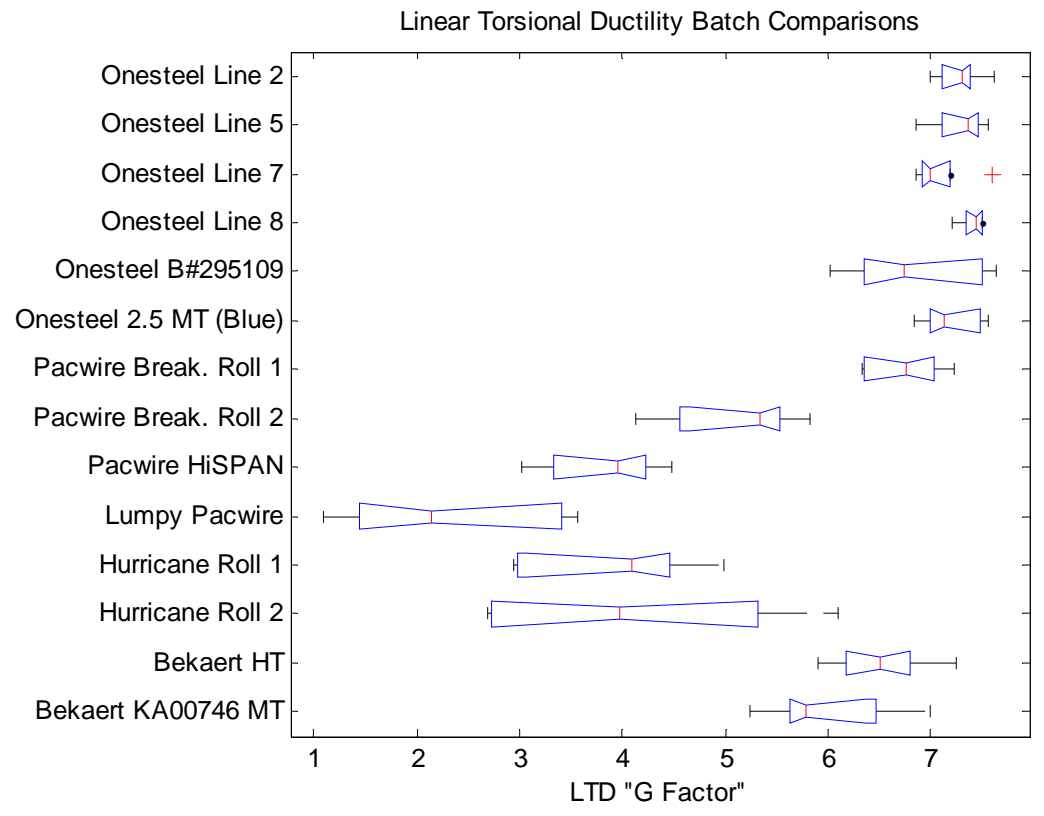

Fig. (8). Boxplot for linear torsional ductility test results. 


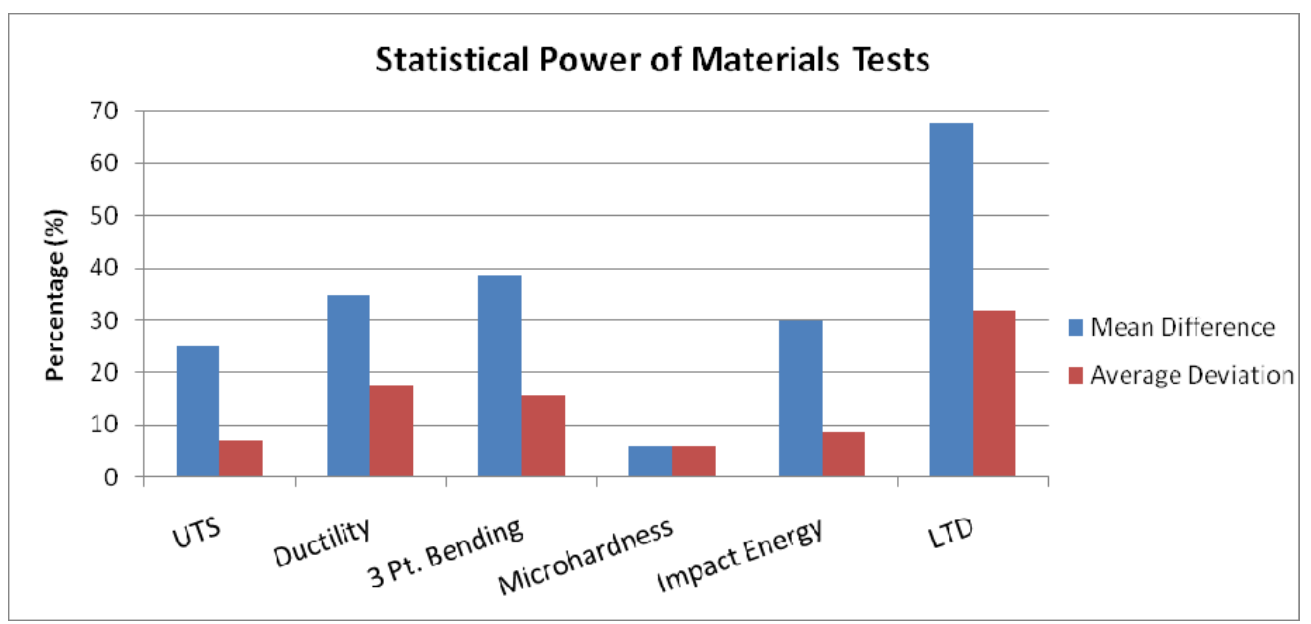

Fig. (9). Statistical discrimination power of the five materials tests conducted on wire specimens. This is represented by mean difference, the ability of the test to differentiate 'best' and 'worst' means, and the average deviation for the test's sample size.

Higher G Factors are therefore preferable to maintain high quality fence production.

\section{Recommendation to Practitioners}

It is recommended that a wire batch should have a mean G Factor of at least 5.0 on a Linear Torsional Ductility (LTD) test to be considered acceptable for input into a fence knotting machine.

On this basis, the risk of wire failure during fence production can also be estimated. It is the size of the lower tail of the $\mathrm{G}$ Factor distribution below $\mathrm{G}=5$. This is readily determined from the mean and standard deviation, assuming a normal distribution. In practice, this means that a batch of wire with a mean $\mathrm{G}$ Factor above 5 could still result in some failures.

\section{DISCUSSION}

\subsection{Outcomes: What has been Achieved?}

This research has provided results for several different tests, including the novel LTD test. The next question is: 'which of these tests is the best?' In this context 'best' refers to the dual attributes of sufficient statistical power to discriminate between 'good' and 'common' (poor) wire, and ease of use in a production environment.

\subsubsection{Discrimination Power}

The various materials tests are compared in Fig. (9). This plot evaluates both the power (difference in mean) and repeatability (average deviation) in terms of percentages.

The data basis from this plot came from analyzing the results from each materials test. The "mean difference" represents the difference in batch means between the worst and best performer, expressed as a percentage. Thus, if a particular materials test has a higher "mean difference", then it possesses higher resolution power in discriminating wire quality indicators.

The "average deviation" (also known as average absolute deviation) of a data set is the average of the absolute deviations and is a summary statistic of statistical dispersion (variability). In this situation, the average deviation has been implemented to give an indication of the expected variability for the particular materials test, and has been expressed as a percentage of the overall test mean.

The statistically ideal test is one with a large mean (easier to detect the difference), and a proportionally small deviation (provide consistent test results). This immediately eliminates micro-hardness, on both counts. The main contenders are LTD, Ductility, and UTS, in that order.

\subsubsection{Specificity and Sensitivity}

Another way of ranking the diagnostic ability of the tests is to determine the specificity and sensitivity. High Specificity is desirable as it means the test successfully detects known deficient wire (true negatives) and does not let defects slip through (false positives). It has low type I error.

High sensitivity is also desirable as it is a measure of whether the test does pass known adequate wire (true positives) and does not fail perfectly good product (false negatives). It has low type II error.

The difficulty with determining specificity and sensitivity is the need to be certain about the identity of the good and bad wire batches, and have a clear threshold for pass (fail). Neither of these factors is beyond dispute in this project, and within these limitations the results for the various wire tests are shown in Fig. (10).

The ideal test would have high specificity and high sensitivity. The results show that UTS, the commonly used measure, has reasonable sensitivity but poor specificity: thus it is weak at detecting known deficient wire and can let defects slip through. Impact energy had the best specificity, but had the opposite problem of mediocre sensitivity: it can fail perfectly good product. Overall, the test that comes out best on these criteria is LTD.

\subsubsection{Applicability to Production Setting}

The operationally ideal test is one that is quick to perform (gives rapid feedback), non complex (easy and unambiguous for plant operators to perform), inexpensive regarding consumables, and undemanding of financial capital. This again eliminates micro-hardness. The main contenders are Impact energy, LTD, and UTS. 


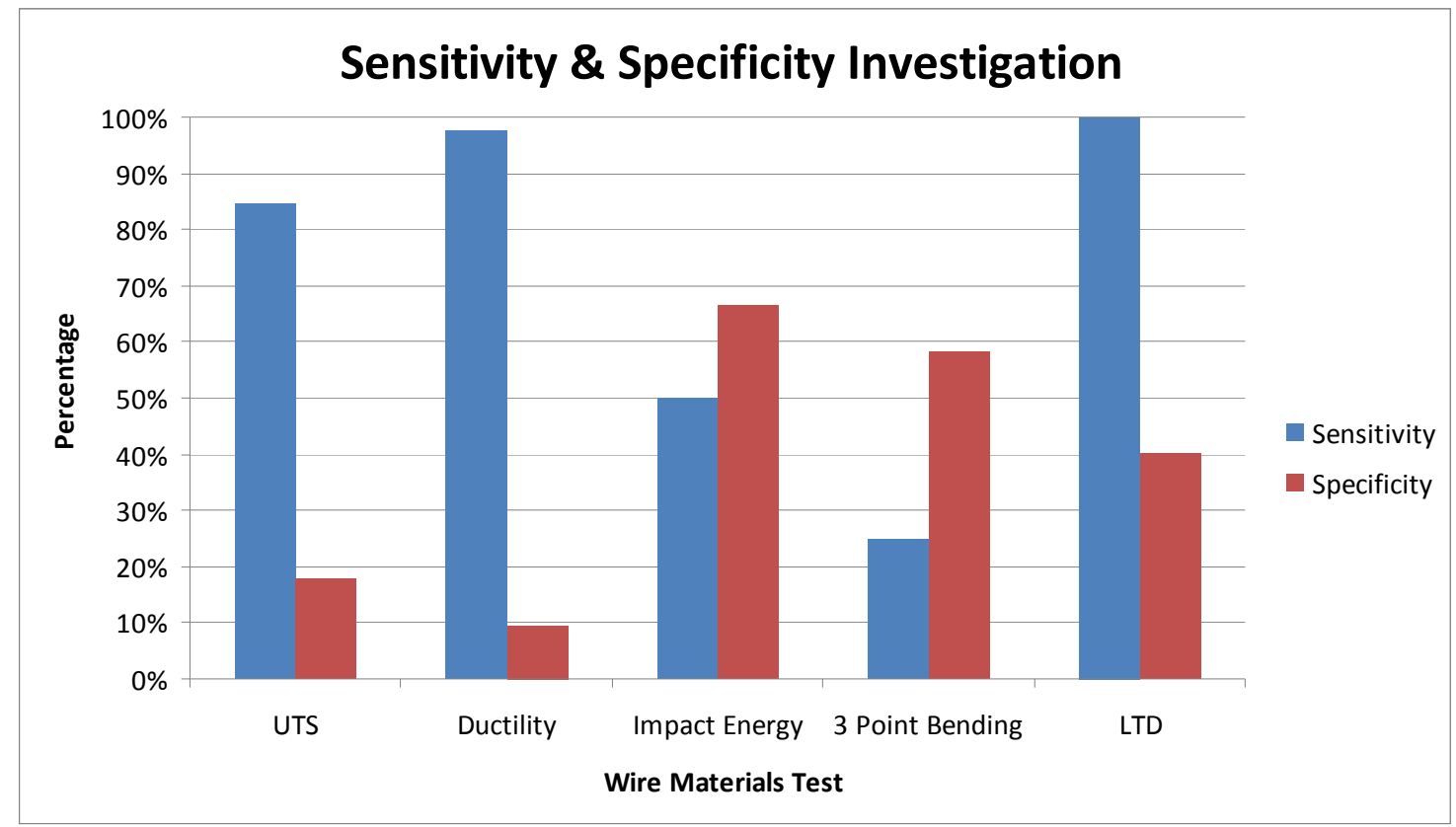

Fig. (10). Specificity and Sensitivity of various wire tests. The ideal is for a test to be high on both measures, and the LTD test is closest to this.

Taken together, LTD emerges as the best candidate for an additional test of wire quality (UTS is already being measured and is demonstrable insufficient on its own).

\section{Recommendation to Practitioners}

It is recommended that LTD be used as an additional test of wire quality.

\subsection{Implications for Industry Practitioners}

In this context 'industry practitioners' refers to Wire Producers and Fence Producers. The implications of this research are as follows:

It is recommended that LTD be used as an additional test of wire quality.

It is recommended that a wire batch should have a mean G Factor of at least 5.0 to be considered acceptable for input into a fence knotting machine.

Details are provided in a companion paper for the construction and operation of the LTD test.

\subsection{Limitations}

The limitations of the LTD test are that it is still in prototype form. The next step from here will be to develop a mechanical wire wrapping unit, capable of consistently forming springs for testing. By removing wrapping variables, the actual power of this test can be evaluated. Also required for operational use is a detailed design for simple method for tensioning the specimens, e.g. a hydraulic puller.

\subsection{Implications for Further Research}

The research suggests that there is not a single material property that defines wire quality or performance. Even though the newly developed linear torsional ductility test seems to explain wire quality the best, we believe that only through evaluating a basket of wire properties, can we truly begin to understand if a certain wire batch is suitable for fence fabrication and subsequent erection. From this report, our "basket of properties" would most likely take UTS, ductility, impact energy and torsional effects (LTD) into consideration.

Our present thinking is that a statistical load-capability inference model could be used to assess the performance of a given wire batch. The performance measure would be in the form of a "safety margin" (or probability), that assesses the likelihood that a wire batch is sufficient for input into a fencing machine.

If there are multiple wire properties to be considered, and a probabilistic approach is to be adopted, then there is the additional challenge of determining a sufficiently powerful method to combine all individual safety margins to give an overall ranking. This is important if such tests are to add value to industry practitioners, i.e. be relevant.

\section{CONCLUSIONS}

Five potential tests were evaluated: UTS, ductility, 3point bending, microstructural, impact energy and linear torsional ductility (LTD). From these tests, it was evident that the linear torsional ductility test was the most sensitive and reliable indicator for wire quality.

\section{CONFLICT OF INTEREST}

The authors confirm that this article content has no conflicts of interest.

\section{ACKNOWLEDGEMENT}

Declared none.

\section{REFERENCES}

[1] BSI, "Specification for fences," British Standards Institution- British Standard, p. 20, 1963.

[2] ASTM, "Annual Book of ASTM Standards, Part 3: In: Steel Plate, Sheet, Strip And Wire; Metallic Coated Products; Fences," Annual Book of ASTM Standards, USA. 1981. 
[3] Anon, "Atmospheric corrosion tests on wire and wire products begun by A.S.T.M," Steel, vol. 99, p. 5154, 1936.

[4] W. H. Bleecker, "Choice of fencing material affected by atmospheric conditions," Oil Gas J., vol. 36, p. 48, 1938.

[5] C. C. Crane, "New electro-galvanizing process for round wire," Steel, vol. 100, pp. 71-72, 1937.

[6] B. A. Jennings, "Fence exposure tests," Agr. Eng., vol. 25, pp. 140141,1944

[7] F. M. Reinhart, "Twenty-year atmospheric corrosion investigation of zinc-coated and uncoated wire and wire products," American Society for Testing and Materials -- Special Technical Publications, p. $141,1961$.

[8] J. L. Schueler, "New process for making zinc coated farm fencing more durable," Agr. Eng., vol. 14, pp. 339-340, 1933.

[9] O. W. Storey, "The corrosion of fence wire," Trans. Am Electrochem. Soc., vol. 32, p.p 211-238, 1917.

[10] R. Nuenninghoff and K. Sczepanski, "Galfan - an improved corrosion protection for steel wire. Part 2: Applications of aluminiumzinc coated steel wires and tests with coated products," Wire, vol. 37, pp. 321-324, 1987.

[11] R. Fabien, M. Robertson, and A. V. Nguyen, "Study on parameters influencing the corrosion of metallic coatings on wire exposed to marine environments," Wire J. Int., vol. 40, pp. 94-8, 2007.
[12] Anon, "Ring-lock wire-fence making machine," Engineering, vol. 133, p. 309, 1932.

[13] S. S. DeForest, "Development of fence erecting machine," Agr. Eng., vol. 42, pp. 66-67, 1961

[14] C. Hamann, "Wire crimping - Das Drahtkroepfen," Draht, vol. 12 pp. $155-160,1961$.

[15] C. E. Hann, D. Aitchison, D. Kirk, and E. Brouwers, "Modelling and system identification of a stiff stay wire fence machine," Proc. Inst. Mech. Eng. B-J Eng., vol. 224, pp. 1069-83, 2010.

[16] AS, "AS 1650-1989 Hot-dipped galvanized coatings on ferrous articles ": Australian Standards 1650.

[17] SNZ, "NZS 3471:1974A1 - Specification for Galvanised Steel fencing wire," Standards New Zealand, Wellington, NZS 3471.

[18] BSI, "BS EN 10223-5:1998 - Steel wire and wire products for fences. Steel wire woven hinged joint and knotted mesh fencing," British Standards Institute (BSI) BS EN 10223

[19] SNZ, "NZS 3471:1974A1 - Specification for Galvanised Steel fencing wire," Standards New Zealand, Wellington, NZS 3471.

[20] BSI, "BS EN 10218-1:1994 - Steel wire and wire products - General test methods," British Standards Institute (BSI) BS EN 10218.

[21] ISO, "ISO 7802-1983 - Metallic Materials - Wire - Wrapping Test," International Organization for Standardization, 7802.

(C) Pons et al.; Licensee Bentham Open.

This is an open access article licensed under the terms of the Creative Commons Attribution Non-Commercial License (http://creativecommons.org/licenses/by-nc/3.0/) which permits unrestricted, non-commercial use, distribution and reproduction in any medium, provided the work is properly cited. 